Article

\title{
Chemical Composition of Pinus roxburghii Bark Volatile Oil and Validation of Its Anti-Inflammatory Activity Using Molecular Modelling and Bleomycin-Induced Inflammation in Albino Mice
}

\author{
Rola M. Labib ${ }^{1,2, *}$, Fadia S. Youssef ${ }^{1}$, Mohamed L. Ashour ${ }^{1}$ (i), Mohamed M. Abdel-Daim ${ }^{3}$ \\ and Samir A. Ross 2,4 \\ 1 Department of Pharmacognosy, Faculty of Pharmacy, Ain-Shams University, Cairo 11566, Egypt; \\ fadiayoussef@pharma.asu.edu.eg (F.S.Y.); ashour@pharma.asu.edu.eg (M.L.A.) \\ 2 National Center for Natural Products Research, University of Mississippi, University, MS 38677, USA; \\ sross@olemiss.edu \\ 3 Department of Pharmacology, Faculty of Veterinary Medicine, Suez Canal University, Ismailia 41522, Egypt; \\ abdeldaim.m@vet.suez.edu.eg \\ 4 Department of BioMolecular Sciences, School of Pharmacy, University of Mississippi, University, \\ MS 38677, USA \\ * Correspondence: rolamilad@pharma.asu.edu.eg; Tel.: +20-1-001-971-922
}

Received: 5 August 2017; Accepted: 19 August 2017; Published: 29 August 2017

\begin{abstract}
The chemical composition of Pinus roxburghii bark essential oil (PRO) was qualitatively and quantitatively determined using GC/FID and GC/MS. The anti-inflammatory activity was assessed in vitro by evaluating the binding percentages on the cannabinoids and opioids receptors. Bleomycin (BLM)-induced pulmonary inflammation in albino mice was adopted to assess PRO anti-inflammatory efficacy in vivo. In silico molecular modelling of its major components was performed on human glucocorticoids receptor (GR). Seventy-five components were identified in which longifolene $(33.13 \%)$ and palmitic acid $(9.34 \%)$ constituted the predominant components. No binding was observed on cannabinoid receptor type 1 (CB1), whereas mild binding was observed on cannabinoid receptor type 2 (CB2), delta, kappa, and $m u$ receptors accounting for $2.9 \%, 6.9 \%, 10.9 \%$ and $22 \%$ binding. A significant in vivo activity was evidenced by reduction of the elevated malondialdehyde (MDA), nitric oxide (NO), myeloperoxidase (MPO), interleukin-6 (IL-6), and tumor necrosis factor- $\alpha$ (TNF- $\alpha$ ) levels by $55.56 \%, 55.66 \%, 64.64 \%, 58.85 \%$ and $77.78 \%$ with concomitant elevation of superoxide dismutase (SOD) and catalase (CAT) activities comparable to BLM-treated group at $100 \mathrm{mg} / \mathrm{kg}$ body weight. In silico studies showed that palmitic acid exerted the fittest binding. PRO could serve as a potent anti-inflammatory natural candidate that should be supported by further clinical trials.
\end{abstract}

Keywords: anti-inflammatory activity; bleomycin; gas-chromatography; molecular modelling; Pinus roxburghii; Pinaceae discipline

\section{Introduction}

Inflammation is the natural body response to injury of cells caused by numerous factors comprising infections, mechanical, and thermal injuries in addition to chemicals [1] that cause severe tissue damage and localized edema [2]. Meanwhile, essential oils represent volatile secondary metabolites that are normally produced within special cells or glands by medicinal plants. They are highly popular of possessing various biological activities comprising anti-inflammatory activity offering a relatively safe, effective, and low-cost medication [3]. On the contrary, the commonly used synthetic anti-inflammatory agent, non-steroidal anti-inflammatory drugs (NSAIDs), provoke a 
lot of serious side effects including gastro-intestinal ulceration, bleeding, renal dysfunction together with destruction of joint and cartilage owing to their nonselective prohibition of COX-1 and COX-2 enzymes [4].

Pinus roxburghii Sarg, belonging to family Pinaceae, is commonly named by "Chir pine" and is native to the Himalaya. It exists as a large ornamental tree nearly $30-50 \mathrm{~m}$ high possessing a trunk of about $2 \mathrm{~m}$ in diameter. It is found at 500 to $2500 \mathrm{~m}$ above the sea level growing gregariously [5]. Traditionally, it was widely employed as an antiseptic, diaphoretic, and a diuretic agent, in addition to exerting tonic and pronounced vermifuge and rubefacient activities [6,7]. The oil of the plant was greatly utilized in various herbal preparation for relieving inflammatory disorders [5].

Nowadays, it shows various prominent biological and pharmacological activities including antioxidant, anti-inflammatory, hepatoprotective, antidyslipidemic, in addition to alleviation of bronchitis, ear, eye, blood, throat, and skin diseases. Besides, its gum showed promising analgesic, aphrodisiac, anthelmintic, carminative, diuretic, expectorant, emmenagogue, and purgative activities $[5,8,9]$.

The chief active constituents of the bark include $\beta$-sitostertol, ceryl alcohol, and friedelin, whereas abietic acid and isopimaric acid were obvious in xylem vessels. The predominant chemical constituents of $P$. roxburghii turpentine oil are $\alpha$-pinene, $\beta$-pinene, car-3-ene, as well as longifolene to which many of its biological activities could be attributed [6]. Moreover, Pinus roxburghii needle oil from Pakistan showed nine components in which $\alpha$-pinene, caryophyllene, and 3-carene predominate, while its stem oil formed of 17 components with the same three previously mentioned components but which differ in their relative quantities [10].

Although Pinus species are highly popular of possessing essential oils with an attractive medicinal value [11-13], few were found in the current literature concerning the chemical composition and the biological activity of the essential oil of Pinus roxburghii bark growing in Egypt. Thus, the foregoing study aimed to qualitatively and quantitatively identify the volatile oil composition isolated from Pinus roxburghii bark. Evaluation of its anti-inflammatory properties in vitro through assessing the inhibitory effect on the cannabinoids and opioids receptors was performed for the first time. Additionally, in vivo assessment using bleomycin-induced inflammation in albino mice was first to be adopted to consolidate its ethnopharmacological anti-inflammatory importance. Moreover, an in silico molecular docking study of the major essential oil components was performed on human glucocorticoids receptor (GR) in an effort to verify its potential mode of action.

\section{Results and Discussion}

\subsection{Chemical Composition of P. roxburghii Bark Essential Oil (PRO)}

A detailed investigation of the essential oil obtained from P. roxburghii bark cultivated in Egypt applying GC-FID and GC/MS techniques resulted in the identification of 75 components representing $89.65 \%$ of the total hydrodistilled oil. The oil is yellow in color with an aromatic odor, giving a yield of $0.022 \% w / w$ of dry plant. The chemical composition of the essential oil was listed in Table 1 . The essential oil was predominated by sesquiterpene hydrocarbons accounting for $37.13 \%$ whereas monoterpenes, oxygenated monoterpenes, oxygenated sesquiterpenes, and other compounds represent $7.75 \%, 6.24 \%, 19.79 \%$ and $18.74 \%$ of the total oil components, respectively.

The major components were longifolene $(33.13 \%)$, palmitic acid $(9.34 \%)$, longicamphenylone (7.88\%), 7(11)-Selinen- $4 \alpha$-ol (4.37\%), and humulane-1,6-dien-3-ol (4.28\%) as shown in Figure 1. Results verified that the sesquiterpene hydrocarbon, longifolene, is the prevalent component in P. roxburghii bark cultivated in different regions. However, the essential oil components vary quantitatively and qualitatively regarding the used organs as well as the geographical origin $[10,14]$. 
Table 1. Volatile constituents identified in Pinus roxburghii bark essential oil (PRO).

\begin{tabular}{|c|c|c|c|c|c|}
\hline & \multirow{2}{*}{ Component } & \multicolumn{2}{|c|}{ RI } & \multirow{2}{*}{ Content $(\%)$} & \multirow{2}{*}{$\begin{array}{l}\text { Identification } \\
\text { Method }\end{array}$} \\
\hline & & Calculated & Reported & & \\
\hline 1 & $\alpha$-Thujene & 922 & 922 & tr. & MS, RI \\
\hline 2 & $\alpha$-Pinene & 929 & 929 & 2.21 & MS, RI \\
\hline 3 & Camphene & 945 & 945 & 0.17 & MS, RI \\
\hline 4 & 1-Isopropyl-4-methylenebicyclo[3.1.0]hex-2-ene & 951 & 952 & 0.19 & MS, RI \\
\hline 5 & 1,2,4-Trimethylbenzene & 995 & 994 & tr. & MS, RI \\
\hline 6 & 3-Carene & 1013 & 1013 & 1.5 & MS, RI \\
\hline 7 & Isocineole & 1018 & 1018 & tr. & MS, RI \\
\hline 8 & $\alpha$-Terpinene & 1019 & 1019 & 0.09 & MS, RI \\
\hline 9 & $\rho$-Cymene & 1025 & 1025 & 0.25 & MS, RI \\
\hline 10 & o-Cymene & 1027 & 1026 & 0.87 & MS, RI \\
\hline 11 & D-Limonene & 1031 & 1031 & 0.37 & MS, RI \\
\hline 12 & Eucalyptol ( $p$-Cineole) & 1034 & 1034 & tr. & MS, RI \\
\hline 13 & trans-Bicyclo[4.4.0]Decane & 1057 & 1056 & 0.1 & MS, RI \\
\hline 14 & $\tau$-Terpinene & 1062 & 1062 & 0.32 & MS, RI \\
\hline 15 & 2-Methyldecane & 1066 & 1063 & tr. & MS, RI \\
\hline 16 & Terpinolene & 1094 & 1093 & 1.97 & MS, RI \\
\hline 17 & $n$-Undecane & 1102 & 1100 & 0.34 & MS, RI \\
\hline 18 & n-Nonanal & 1108 & 1108 & 0.17 & MS, RI \\
\hline 19 & $\alpha$-Thujone & 1110 & 1110 & 0.06 & MS, RI \\
\hline 20 & Fenchol, exo- & 1119 & 1119 & 0.14 & MS, RI \\
\hline 21 & L-trans-Pinocarveol & 1144 & 1143 & 0.95 & MS, RI \\
\hline 22 & Camphor & 1150 & 1150 & 0.18 & MS, RI \\
\hline 23 & Isoborneol & 1163 & 1162 & tr. & MS, RI \\
\hline 24 & $\alpha$-Phellandren-8-ol & 1166 & 1166 & 0.23 & MS, RI \\
\hline 25 & Pincarvone & 1169 & 1164 & 0.46 & MS, RI \\
\hline 26 & Borneol & 1172 & 1173 & tr. & MS, RI \\
\hline 27 & $p$-Acetyltoluene & 1178 & 1179 & 0.22 & MS, RI \\
\hline 28 & 1-Terpinen-4-ol & 1183 & 1183 & 0.84 & MS, RI \\
\hline 29 & p-Cymen-8-ol & 1187 & 1187 & 0.31 & MS, RI \\
\hline 30 & $\tau$-Terpineol & 1196 & 1192 & 0.95 & MS, RI \\
\hline 31 & Myrtenal & 1202 & 1204 & 1.4 & MS, RI \\
\hline 32 & $n$-Decanal & 1209 & 1209 & tr. & MS, RI \\
\hline 33 & cis-Carveol & 1226 & 1226 & 0.12 & MS, RI \\
\hline 34 & Acetophenone, $2^{\prime}, 4^{\prime}$-dimethyl & 1229 & 1230 & 0.09 & MS, RI \\
\hline 35 & Cumin aldehyde & 1248 & 1248 & 0.16 & MS, RI \\
\hline 36 & $n$-Nonanoic acid & 1282 & 1282 & tr. & MS, RI \\
\hline 37 & Thymol & 1304 & 1304 & tr. & MS, RI \\
\hline 38 & Carvacrol & 1311 & 1311 & tr. & MS, RI \\
\hline 39 & 2,4-Decadienal & 1324 & 1322 & tr. & MS, RI \\
\hline 40 & $\alpha$-Terpinyl acetate & 1357 & 1356 & 0.44 & MS, RI \\
\hline 41 & $\alpha$-Longipinene & 1360 & 1360 & 0.63 & MS, RI \\
\hline 42 & $n$-Decanoic acid & 1376 & 1376 & tr. & MS, RI \\
\hline 43 & Longicyclene & 1381 & 1380 & 2.18 & MS, RI \\
\hline 44 & $\alpha$-Ylangene & 1385 & 1385 & tr. & MS, RI \\
\hline 45 & (+)-Sativen & 1399 & 1391 & 0.87 & MS, RI \\
\hline 46 & $\beta$-Caryophyllene & 1411 & 1411 & 0.32 & MS, RI \\
\hline 47 & D-longifolene & 1419 & 1418 & 33.13 & MS, RI \\
\hline 48 & $n$-Undecanoic acid & 1444 & 1445 & tr. & MS, RI \\
\hline 49 & $\alpha$-Humulene & 1467 & 1468 & tr. & MS, RI \\
\hline 50 & Dodecanoic acid & 1576 & 1578 & 2.53 & MS, RI \\
\hline 51 & (+)-Longicamphenylone & 1580 & 1563 & 7.88 & MS, RI \\
\hline 52 & Globulol & 1586 & 1587 & 0.72 & MS, RI \\
\hline 53 & Caryophyllene oxide & 1594 & 1594 & 1.66 & MS, RI \\
\hline 54 & Viridiflorol & 1608 & 1609 & tr. & MS, RI \\
\hline 55 & Humulane-1,6-dien-3-ol & 1615 & 1619 & 4.28 & MS, RI \\
\hline 56 & Tridecanoic acid & 1643 & 1645 & 0.42 & MS, RI \\
\hline 57 & Longiverbenone & 1670 & 1678 & tr. & MS, RI \\
\hline 58 & $\alpha$-Santalol & 1689 & 1683 & 0.88 & MS, RI \\
\hline 59 & $7(11)$-Selinen- $4 \alpha$-ol & 1700 & 1688 & 4.37 & MS, RI \\
\hline 60 & Pentadecanal & 1722 & 1717 & tr. & MS, RI \\
\hline
\end{tabular}


Table 1. Cont.

\begin{tabular}{|c|c|c|c|c|c|}
\hline & \multirow{2}{*}{ Component } & \multicolumn{2}{|c|}{ RI } & \multirow{2}{*}{ Content $(\%)$} & \multirow{2}{*}{$\begin{array}{c}\text { Identification } \\
\text { Method }\end{array}$} \\
\hline & & Calculated & Reported & & \\
\hline 61 & Myristic acid & 1774 & 1774 & 1.84 & MS, RI \\
\hline 62 & Octadecane & 1802 & 1800 & 0.06 & MS, RI \\
\hline 63 & $n$-Pentadecanoic acid & 1873 & 1872 & 0.97 & MS, RI \\
\hline 64 & Nonadecane & 1904 & 1900 & 0.16 & MS, RI \\
\hline 65 & Palmitic acid, methyl ester & 1926 & 1926 & tr. & MS, RI \\
\hline 66 & 9-Hexadecenoic acid & 1953 & 1957 & 0.51 & MS, RI \\
\hline 67 & Palmitic acid & 1979 & 1975 & 9.34 & MS, RI \\
\hline 68 & $n$-Eicosane & 2002 & 2000 & tr. & MS, RI \\
\hline 69 & 1-Octadecanol & 2096 & 2086 & 1.23 & MS, RI \\
\hline 70 & $n$-Heneicosane & 2109 & 2100 & 0.57 & MS, RI \\
\hline 71 & $n$-Docosane & 2211 & 2200 & tr. & MS, RI \\
\hline 72 & $n$-Tricosane & 2304 & 2300 & tr. & MS, RI \\
\hline 73 & $n$-Tetracosane & 2403 & 2400 & tr. & MS, RI \\
\hline 74 & $n$-Pentacosane & 2509 & 2500 & tr. & MS, RI \\
\hline 75 & $n$-Hexacosane & 2610 & 2600 & tr. & MS, RI \\
\hline \multicolumn{2}{|c|}{ Monoterpene hydrocarbons } & & & 7.75 & \\
\hline \multicolumn{2}{|c|}{ Oxygen containing monoterpene } & & & 6.24 & \\
\hline \multicolumn{2}{|c|}{ Sesquiterpene hydrocarbons } & & & 37.13 & \\
\hline \multicolumn{2}{|c|}{ Oxygen containing sesquiterpene } & & & 19.79 & \\
\hline \multicolumn{2}{|c|}{ Others } & & & 18.74 & \\
\hline \multicolumn{2}{|c|}{ Total identified components } & & & 89.65 & \\
\hline
\end{tabular}

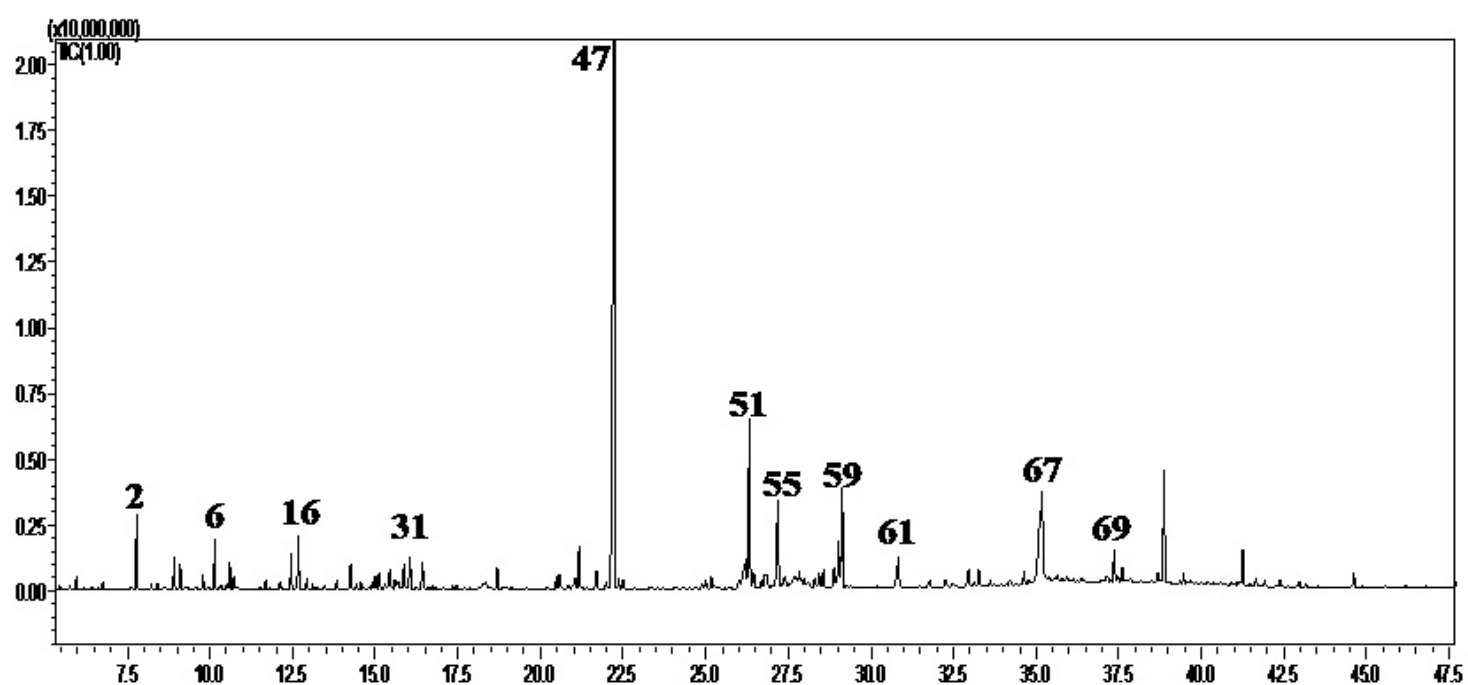

Figure 1. GC-chromatogram obtained with a Rtx-5MS column of the essential oil constituents isolated by hydrodistillation from Pinus roxburghii bark.

\subsection{In Vitro Anti-Inflammatory Activity of PRO}

Concerning the anti-inflammatory activity of the essential oil, it was previously reported that an effective anti-inflammatory therapy could be achieved by its concomitant administration with analgesics [15]. Analgesic agents achieved their targeted effects by acting with plethora of mechanisms on the central and/or peripheral nervous systems. These mechanisms may include the inhibition of prostaglandins synthesis through the interference with the cyclooxygenase and lypoxygenase pathways either peripherally or centrally. Moreover, prohibition of G-protein-mediated signal transduction, induction of endogenous opioid peptides, blockage of 5-hydroxytryptamine release, and inhibition of excitatory amino acids or $N$-methyl-D-aspartate receptor activation have been also reported [16,17]. Well-known analgesic drugs comprise paracetamol, NSAIDs exemplified by salicylates, in addition 
to cannabinoids and opioids, such as morphine. Synthetic anti-inflammatory agents, particularly NSAIDs, that are widely employed for the relief of pain and inflammation provoke a lot of serious side effects. Thus, in vitro analgesic and the anti-inflammatory activities herein were examined via acting on the cannabinoid receptors, CB1 that exists in the central nervous system and CB2 that is present in the peripheral tissues in addition to the opioid receptors [18]. Thus, the binding percentages of the essential oil on the cannabinoids (CB1 and CB2) and opioids ( $m u$, delta, and kappa) receptors were evaluated. Results showed that no binding was observed on CB1 receptors, whereas mild to moderate binding was observed on CB2, delta, kappa, and $m u$ receptors accounting for are $2.9 \%, 6.9 \%, 10.9 \%$, and $22 \%$ binding respectively as recorded in Table S1.

\subsection{In Vivo Anti-Inflammatory Activity of PRO}

Regarding in vivo anti-inflammatory effect, a potent effect of the essential oil in alleviating oxidative stress markers was observed. There was a significant increase in MDA and NO (nitric oxide) levels. Additionally, a pronounced decrease in SOD and CAT activities in the lung homogenate of BLM-treated group compared to the control group was observed. Administration of PRO significantly reduced the elevated MDA and NO levels by $55.56 \%$ and $55.66 \%$ compared to the BLM-treated group at a dose of $100 \mathrm{mg} / \mathrm{kg}$ body weight. Meanwhile, SOD and CAT were significantly increased in a dose-dependent manner with $72 \%$ and $108 \%$ increase relative to BLM-treated group at a dose of $100 \mathrm{mg} / \mathrm{kg}$ body weight, as recorded in Figure 2.

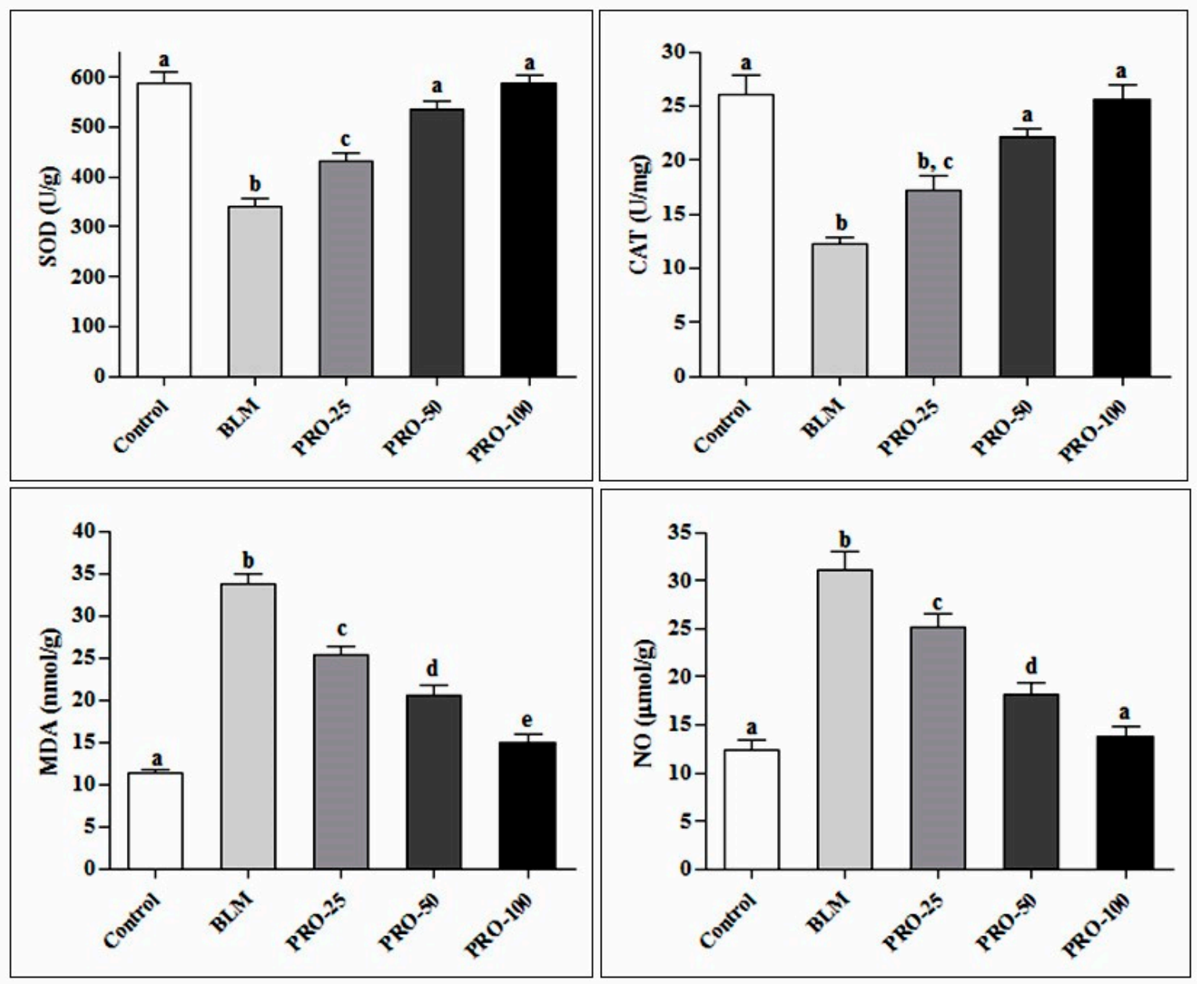

Figure 2. Effect of the PRO on oxidative stress markers (SOD, CAT, MDA, and NO) in lung tissue homogenate of BLM-treated mice. Different superscripts refer to significance at $p \leq 0.05(n=6)$. 
Additionally, the levels of proinflammatory cytokines MPO, IL-6, and TNF- $\alpha$ were significantly increased in the BLM-treated group compared to the control group. MPO increase was ameliorated by PRO at doses of 50 and $100 \mathrm{mg} / \mathrm{kg}$, showing $36.49 \%$ and $64.64 \%$ decline comparable to the BLM-treated group in the previously mentioned doses, respectively. Moreover, the elevation of IL- 6 and TNF- $\alpha$ levels were significantly lowered by PRO in a dose-dependent level, showing 58.85\% and $77.78 \%$ decline relative to the negative control group at $100 \mathrm{mg} / \mathrm{kg}$ body weight, as shown in Table 2 .

Table 2. Effect of the PRO on the inflammatory markers in lung tissue homogenate of BLM-treated mice.

\begin{tabular}{|c|c|c|c|c|c|}
\hline & Control & BLM & PRO-25 & PRO-50 & PRO-100 \\
\hline MPO (pg/g) & $23.21 \pm 1.07^{a}$ & $88.99 \pm 3.30^{b}$ & $78.87 \pm 5.47^{b}$ & $56.52 \pm 2.31^{\mathrm{c}}$ & $31.47 \pm 2.36^{\mathrm{a}}$ \\
\hline IL-6(pg/g) & $192.63 \pm 14.85^{\mathrm{a}}$ & $775.38 \pm 44.07^{b}$ & $640.46 \pm 16.94^{c}$ & $453.46 \pm 29.04^{d}$ & $319.05 \pm 25.06^{\mathrm{e}}$ \\
\hline TNF- $\alpha(\mathrm{pg} / \mathrm{mL})$ & $47.49 \pm 2.84^{\mathrm{a}}$ & $377.53 \pm 16.57^{b}$ & $235.51 \pm 14.71^{\mathrm{c}}$ & $169.76 \pm 9.59^{d}$ & $83.87 \pm 4.43^{\mathrm{e}}$ \\
\hline
\end{tabular}

Different superscripts within the same row refer to significance at $p \leq 0.05(n=6)$.

The histopathological assessments of pulmonary inflammation and fibrosis recorded in bleomycin and other treated groups are demonstrated in Table 3.

Table 3. Effect of the PRO on pathological score of pulmonary inflammation and fibrosis in BLM-treated mice.

\begin{tabular}{cc}
\hline Group & Score \\
\hline Saline & $0.20 \pm 0.20^{\mathrm{a}}$ \\
BLM & $2.60 \pm 0.24^{\mathrm{c}}$ \\
PRO-25 & $2.20 \pm 0.37^{\mathrm{c}}$ \\
PRO-50 & $1.40 \pm 0.24^{\mathrm{b}}$ \\
PRO-100 & $1.20 \pm 0.20^{\mathrm{b}}$
\end{tabular}

Results expressed as mean \pm SD. Different superscripts within the same column were significantly different.

Lungs of control mice revealed normal pulmonary parenchyma (Figure 3a) with no evidence of interstitial fibrosis which is confirmed by Masson's trichrome stain (Figure 4a). In contrast, lungs of BLM-treated mice revealed distortion of pulmonary parenchyma with alveolar and interstitial fibrosis scored $2.60 \pm 0.24$, which is characterized by marked thickening of alveolar walls and interstitial tissue by proliferating mononuclear cells, mostly lymphocytes and macrophages, as well as fibroblastic proliferation (Figure 3b) with collagen deposition that appeared intensely blue in Masson's trichrome stained sections (Figure 4b). Most alveoli appeared partially collapsed with partial obliteration of alveolar lumina.

Mild improvement of pulmonary inflammation and fibrosis was demonstrated in the PRO-25 pretreated group, which scored $2.20 \pm 0.37$, in which the interstitial inflammatory infiltrates (Figure 3c) and collagen deposition, which appeared blue in Masson's trichrome stained sections (Figure 4c), were evident. Marked regression of fibrosis and interstitial inflammatory infiltrates was recorded in the PRO-50 and PRO-100 pretreated groups with lesion scores $1.40 \pm 0.24$ and $1.20 \pm 0.20$, respectively. The pulmonary parenchyma of the PRO-50 pretreated group was less distorted with mild interstitial inflammatory cell infiltration (Figure 3d) and no collagen deposition, which is confirmed in Masson's trichrome stained sections (Figure 4d). Lung of PRO-100 pretreated groups appeared normal (Figure 3e) and greatly similar to the control group, and the interstitial inflammatory infiltrates were confined to focal areas which affect less than $25 \%$ of the lung parenchyma. Masson's trichrome stain confirmed no collagen deposition in nearly all of the examined sections (Figure 4e). 


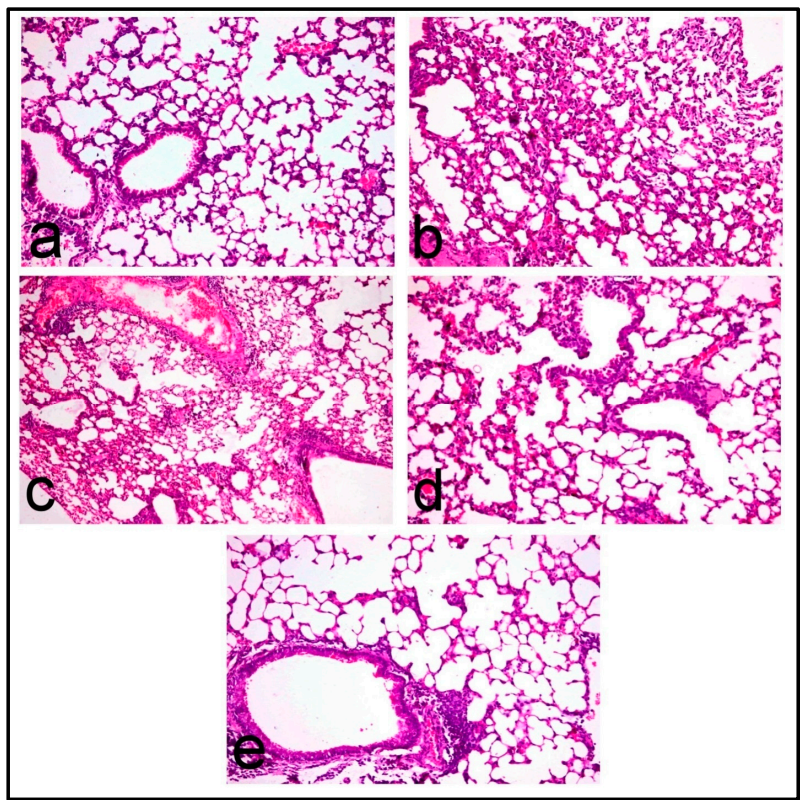

Figure 3. Histopathological images of BLM-induced lung fibrosis in mice; Lung of (a) control mice showing normal pulmonary parenchyma; (b) BLM-treated mice showing marked thickening of alveolar wall and interstitial tissue by proliferating mononuclear cells mostly lymphocytes and macrophages and fibroblastic proliferation; (c) PRO-25 treated mice showing interstitial inflammatory cell infiltrates; (d) PRO-50 treated mice showing less distorted pulmonary parenchyma with mild interstitial inflammatory cell infiltration, and (e) PRO-100 treated mice showing normal pulmonary parenchyma. (H\&E, 200×).

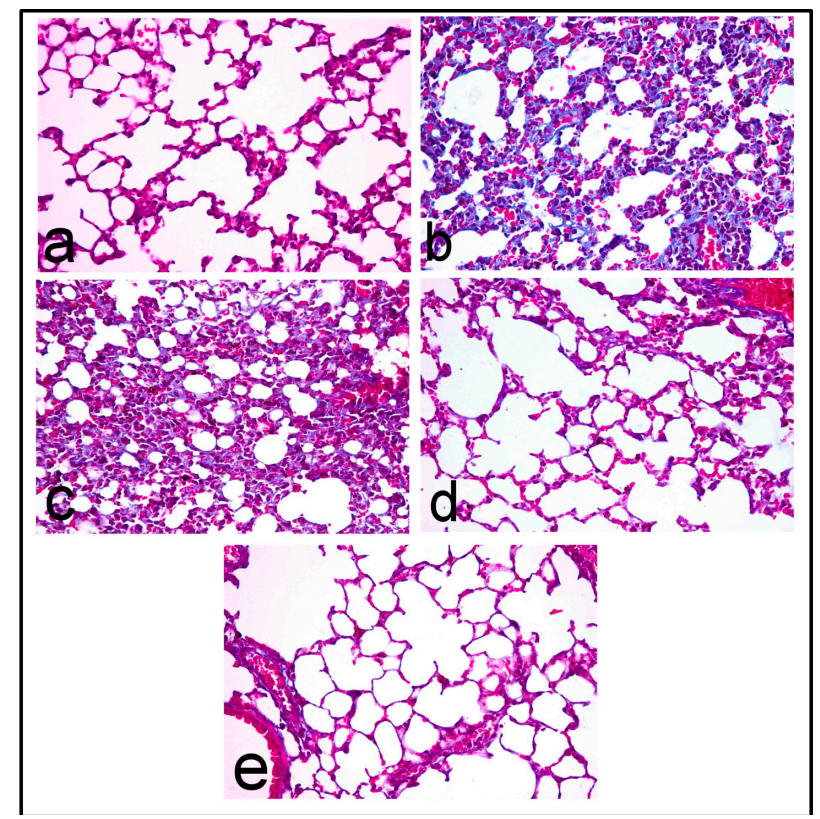

Figure 4. Lung of (a) control mice showing no collagen deposition; (b) BLM-treated mice showing intensely blue collagen fibers; (c) PRO-25 treated mice showing blue stained collagen fibers; (d) PRO-50 treated mice showing no collagen deposition; and (e) PRO-100 treated mice showing no collagen deposition. (Masson's trichrome stain, 400×). 


\subsection{In Silico Molecular Modelling Study of PRO Major Constituents in GR}

Glucocorticoids have long been used in the alleviation of patients suffering from pulmonary fibrosis via prohibition of procollagen synthesis, both in connective tissues and in fibroblasts, in addition to reduction of pulmonary parenchymal cell proliferation. This was explained in virtue of the reversal of type I procollagen mRNA partitioning in polysomes together with reversing stimulation of procollagen synthesis induced by bleomycin $[19,20]$. Thus, molecular docking of the major essential oil components was done within the active site of human glucocorticoids receptors and showed that most of them have affinity to the binding site as compared to the potent anti-inflammatory GR agonist, dexamethasone, and thus can exert a potent anti-inflammatory activity. The free binding energy of these compounds was chosen as a comparison factor in the docking experiments, as recorded in Table 4 .

Table 4. Binding of the major PRO components to human glucocorticoid receptor (GR) using molecular modeling experiments as manifested by binding energy values $\left(\Delta \mathrm{G}_{\text {binding }}\right)$ expressed in $\mathrm{kcal} / \mathrm{mol}$.

\begin{tabular}{cc}
\hline Compound Name & $\Delta \mathbf{G}_{\text {binding }}$ \\
\hline Dexamethasone & -61.0836 \\
Palmitic acid & -60.2838 \\
1-Octadecanol & -55.3628 \\
Myristic acid & -54.4668 \\
Dodecanoic acid & -49.2119 \\
7(11)-Selinen-4- $\alpha$-ol & -35.5702 \\
Caryophyllene oxide & -34.8706 \\
Humulane-1,6-dien-3-ol & -32.9638 \\
Longicyclene & -31.6995 \\
D-longifolene & -30.3795 \\
Longicamphenylone & -30.0035 \\
Myrtenal & -26.4264 \\
$\alpha$-Pinene & -21.7649 \\
Terpinolene & -21.3438 \\
3-Carene & -21.2806 \\
\hline
\end{tabular}

The validity of the docking study was confirmed by comparing and alignment of the best docked poses of the lead compound, dexamethasone, with the lead conformer co-crystallized with GR. Results revealed a good alignment between them $\left(\mathrm{RMSD}=0.60 \mathrm{~A}^{\circ}\right)$, confirming the validity of the experiment (Figure S1). Among all the docked major constituents, palmitic acid exerted the fittest binding to GR as evidenced from its free binding energy that approaches that of dexamethasone, being -60.28 and $61.08 \mathrm{kcal} / \mathrm{mol}$, respectively. Examining the active site of GR, it showed the presence of many hydrophobic residues. Binding of palmitic acid in the active pocket of human glucocorticoid receptors (GR) is illustrated in Figure 5b. Its firm binding could be explained by virtue of the formation of three hydrogen bonds with the amino acid residues of Arg611 and Gly570, in addition to the hydrophobic interaction with the GR as shown in Figure 5a,b. This may highlight that the essential oil of Pinus roxburghii could partly act in a manner similar to glucocorticoids, owing to the agonist effect of its major constituents within the active site, similarly to dexamethasone. Glucocorticoids are highly potent in relieving inflammation owing to their pleiotropic effects observed on the glucocorticoid receptor affecting multiple signaling pathways. Unfortunately, this pleiotropic behavior may widely affect many metabolic processes causing growth retardation in children and affecting immune system. In addition, hypertension, suppression of wound healing, and osteoporosis are among the common adverse effects of prolonged glucocorticoid regimen [21]. However, essential oil of Pinus roxburghii could alleviate inflammation with minimal observed adverse effects. 


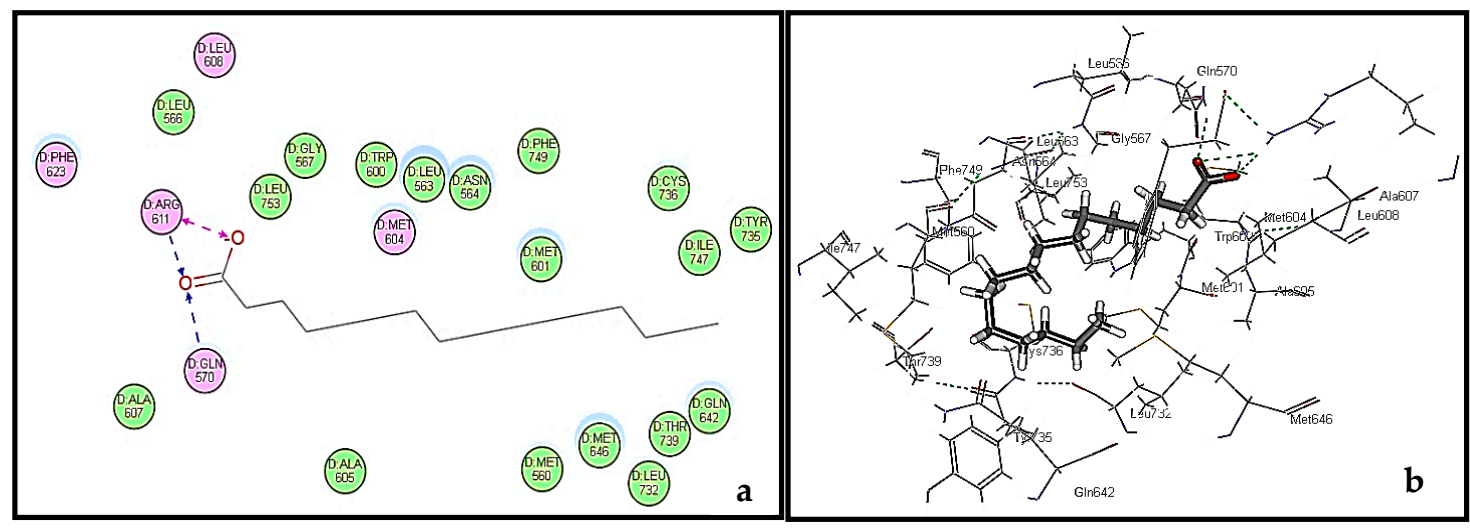

Figure 5. 2D binding mode (a) and 3D binding mode (b) of palmitic acid in the active site of human glucocorticoid receptors (GR).

\section{Materials and Methods}

\subsection{Plant Material}

Pinus roxburghii Sarg. Bark (Pinaceae) was collected from El-Orman Botanical Garden (Giza, Egypt) on April 2014 and authenticated by Mrs. Terease Labib, Consultant of Plant Taxonomy at Ministry of Agriculture, El-Orman Botanical Garden and National Gene Bank, Giza, Egypt. A voucher specimen was deposited in the herbarium of the Pharmacognosy Department, Faculty of Pharmacy, Ain Shams University (P-PR-7).

\subsection{Essential Oil Preparation}

Volatile oil of Pinus roxburghii bark was obtained by hydrodistillation $(250 \mathrm{~g})$ for $4 \mathrm{~h}$ using a Clevenger-type apparatus. The oil was dried over anhydrous sodium sulfate and kept in a sealed vial at $-30^{\circ} \mathrm{C}$ for further analyses. The yield was performed in triplicate, determined based on the initial dried plant weight, and expressed in \% $(w / w)$.

\subsection{Gas Chromatography}

\subsubsection{GC/FID Analysis}

GC/FID analysis was performed using a Shimadzu GC-17A gas chromatograph (Shimadzu Corporation, Kyoto, Japan) supplied with FID detector and a DB-5 fused-bonded cap column (Phenomenex; $29 \mathrm{~m} \times 0.25 \mathrm{~mm}$ i.d., film thickness $0.25 \mu \mathrm{m}$; Torrance, CA, USA). The oven temperature was programmed isothermal at $50{ }^{\circ} \mathrm{C}$ for $2 \mathrm{~min}$, then raised from 50 to $300{ }^{\circ} \mathrm{C}$ at $7{ }^{\circ} \mathrm{C} / \mathrm{min}$, and finally held isothermal at $300{ }^{\circ} \mathrm{C}$ for $10 \mathrm{~min}$; injector temp., $250{ }^{\circ} \mathrm{C}$; detector temp., $300{ }^{\circ} \mathrm{C}$; carrier gas, $\mathrm{He}$ $(1.5 \mathrm{~mL} / \mathrm{min}$ ); with split mode (split ratio, 1:20). The sample $0.1 \mu \mathrm{L}$ was injected automatically to the chromatograph using AOC-20i auto sampler. Class GC $10^{\circledR}$ software (Shimadzu Corporation, Kyoto, Japan) was used for recording and integrating the chromatograms. Average areas under the peaks of three independent chromatographic runs were used for calculating the $\%$ composition of each component (total peak area $=100 \%)$.

\subsubsection{GC/MS Analysis}

Mass spectrum was recorded using Shimadzu GC-2010 plus gas chromatograph (Shimadzu Corporation, Kyoto, Japan) coupled to a quadrupole mass spectrometer Shimadzu QP-2010 equipped with Rtx-5MS fused bonded column $(30 \mathrm{~m} \times 0.25 \mathrm{~mm}$ i.d. $\times 0.25 \mu \mathrm{m}$ film thickness) (Restek, Bellefonte, PA, USA) equipped with a split-splitless injector. The capillary column was directly coupled to a quadrupole mass spectrometer. The initial column temperature was kept at $45^{\circ} \mathrm{C}$ for $2 \mathrm{~min}$ (isothermal) 
and programmed to $300{ }^{\circ} \mathrm{C}$ at a rate of $5{ }^{\circ} \mathrm{C} / \mathrm{min}$, and kept constant at $300{ }^{\circ} \mathrm{C}$ for 5 min (isothermal). Detector and injector temperatures were 300 and $250^{\circ} \mathrm{C}$, respectively. Helium carrier gas flow rate was $2 \mathrm{~mL} / \mathrm{min}$. Mass spectra were recorded applying the following condition: (equipment current) filament emission current, $60 \mathrm{~mA}$; ionization voltage, $70 \mathrm{eV}$; ion source, $200{ }^{\circ} \mathrm{C}$. Diluted samples $(0.5 \% \mathrm{v} / \mathrm{v})$ were injected with split mode (split ratio 1:15). The sample $(1 \mu \mathrm{L})$ was injected automatically to the chromatograph using AOC-20i auto sampler. GC solution ${ }^{\circledR}$ software ver. 2.4 (Shimadzu Corporation, Kyoto, Japan) was used for recording and integrating the chromatograms. Volatile components were identified by comparing their retention indices (RI) and mass spectra with those built in libraries (NIST Mass Spectral Library (December 2005), Wiley Registry of Mass Spectral Data 8th edition) and literature $[22,23]$.

\subsection{In Vitro Anti-Inflammatory Activity Evaluation}

\subsubsection{Cannabinoid Receptor Binding Assay}

For each assay, non-specific binding was determined using $10 \mu \mathrm{M}$ of CP-55,940 as a positive control. Total, specific, and non-specific binding were used to calculate the binding percentage of the non-labeled control to CB1 and CB2 receptors. The membrane concentration exhibiting good binding percentage ( $>90 \%$ ) and total binding with high signal (thousands of CPM) was used as the optimal membrane concentration for the assay [24].

\subsubsection{Opioid Receptor Binding Assay}

Human embryonic kidney cells (HEK293) stably transfected with human opioid receptor subtypes $\mu, \delta$, or $\kappa$ were used to perform the opioid receptor binding assays. For each assay, non-specific binding was determined using $10 \mu \mathrm{M}$ of a positive control [U-69,593 [phenyl-3,4-3H] (K), Enkephalin DPDPE [Tyrosyl-3,5-3H(N)] ( $\delta)$, or DAMGO [Tyrosyl-3,5-3H(N)] $(\mu)$. The dissociation constant [4] for ligands for each receptor was established through a membrane evaluation and saturation binding experiment. Total, specific, and non-specific binding were used to calculate the binding percentage of the non-labeled control to receptor. The membrane concentration exhibiting good binding percentage (>90\%) and total binding with high signal (thousands of CPM) was used as the optimal membrane concentration for the assay [24].

Data of the two assays were analyzed by a non-linear curve fit model using GraphPad Prism 5.04 software (GraphPad, La Jolla, CA, USA) and the Kd value was calculated. General screening was performed using the optimal concentration of membrane with a radioligand concentration less than or equals to the $\mathrm{Kd}$. Each compound was tested at $10 \mu \mathrm{M}$ in triplicates. The assays were performed as stated above. Non-specific binding was subtracted from total binding to find specific binding. Percent binding was determined using the following equation:

$$
\% \text { binding }=100-\left(\frac{\text { Compound } \mathrm{CPM}-\text { nonspecific CPM }}{\text { specific CPM }}\right) \times 100
$$

The competitive binding assay was performed using the optimal concentration of membrane with radioligand concentration equal to the $\mathrm{Kd}$, and 12 concentrations of each compound ranging from 0.032 to $10,000 \mu \mathrm{M}$. Each compound was tested in triplicate. The assays were performed as stated above. The $\mathrm{IC}_{50}$ and $\mathrm{Ki}$ values were calculated by a non-linear curve fit model using GraphPad Prism 5.0 software.

\subsection{In Vivo Anti-Inflammatory Activity Evaluation}

\subsubsection{Drugs, Chemicals, and Kits}

Bleomycin in the form of Blecocip, vial, 15 units was obtained from (Cipla Ltd., Mumbai, India). Kits for evaluating the lipid peroxidation marker, malondialdehyde (MDA), as well as those 
for antioxidant parameters represented by superoxide dismutase (SOD) and catalase (CAT) were bought from Biodiagnostics Co. (Cairo, Egypt). The pro-inflammatory cytokines (IL-6, TNF- $\alpha$ ) were purchased from R\&D Systems GmbH (Wiesbaden, Germany). Myeloperoxidase (MPO) ELISA kits was brought from Hycult Biotechnology, Plymouth Meeting, PA, USA. All other chemicals used were of analytical grade.

\subsubsection{Animals}

Thirty male Swiss albino mice, ten-weeks-old, weighing about $25 \pm 2 \mathrm{~g}$, were purchased from the Egyptian Organization for Biological Products and Vaccines, Giza, Egypt. The animals were reared at Experimental Animal Unit at Faculty of Veterinary Medicine, Suez Canal University, Ismailia, Egypt. They were kept on a 12-h light/dark cycle in a maintained temperature $\left(24 \pm 2{ }^{\circ} \mathrm{C}\right)$ and humidity $(50 \pm 5 \%)$ conditions. All procedures in this animal study were performed according the guidelines of $\mathrm{NIH}$ and approved by Animal Research Ethics committee of Faculty of Veterinary Medicine, Suez Canal University, Ismailia, Egypt (Approval Number:201613).

\subsubsection{Experimental Design}

The animals were divided into 5 groups, each of 6 mice. The first group was given saline and kept as control. The mice in second group were intraperitoneally injected with bleomycin (BLM) at a dose of $15 \mathrm{mg} / \mathrm{kg}$ twice a week for four consecutive weeks [25]. The third, fourth, and fifth groups were intraperitoneally injected with essential oil (PRO) at doses of 25, 50, $100 \mathrm{mg} / \mathrm{kg}$ body weight, respectively. Five days after the last BLM dose, the mice were sacrificed, and lung tissues were harvested. The right lung was rapidly excised, weighed, frozen, and kept at $-80{ }^{\circ} \mathrm{C}$ until used for the assessment of lipid peroxidation marker, MDA, antioxidant enzyme activities; SOD and CAT, as well as the assay of the proinflammatory cytokines; interleukin-6 (IL-6) and tumor necrosis factor alpha (TNF- $\alpha$ ). Moreover, myeloperoxidase (MPO) was estimated as indicator for leucocytic adhesion and infiltration.

\subsubsection{Evaluation of Lipid Peroxidation and Oxidative Stress Markers}

Lung lobes were thawed at $4{ }^{\circ} \mathrm{C}$, homogenized on ice in $50 \mathrm{mM}$ Tris- $\mathrm{HCl}$ buffer containing $180 \mathrm{mM} \mathrm{KCl}$ and $10 \mathrm{mM}$ EDTA, final $\mathrm{pH} 7.4$, and then centrifuged at $10,000 \mathrm{rpm}, 4^{\circ} \mathrm{C}$, for $30 \mathrm{~min}$. Lung homogenates were centrifuged at $860 \mathrm{rpm}$ for $20 \mathrm{~min}$ at $4{ }^{\circ} \mathrm{C}$ and the resultant supernatant was frozen at $-20{ }^{\circ} \mathrm{C}$ and used for assays of different oxidative stress markers. Superoxide dismutase (SOD) was determined according to Nishikimi et al., 1972 [26], catalase (CAT) according to Aebi, 1974 [27], malondialdehyde (MDA) according to Mihara and Uchiyama, 1978 [28].

\subsubsection{Evaluation of the Inflammatory Markers}

Lung homogenate supernatants were used for assay of IL- 6 and TNF- $\alpha$ using Mouse IL- 6 and TNF- $\alpha$ ELISA kit following the protocol provided by the manufacturer. Values are expressed as $\mathrm{pg} / \mathrm{mL}$. Myeloperoxidase (MPO) activity was evaluated as an indicator for leukocyte infiltration and adhesion in many tissues, including the lung. Estimation of MPO activity was carried out according to the manufacturer protocol, and its values are expressed as $\mathrm{pg} / \mathrm{g}$ tissue.

\subsubsection{Histological Study}

Ten lung sections per group were fixed in $10 \%$ neutral formalin, washed, and embedded in paraffin blocks. $5 \mu \mathrm{m}$ thick sections were stained with H\&E to demonstrate the pulmonary fibrosis and inflammation, and Masson's trichrome stains to demonstrate collagen deposition. Semi-quantitative lesion scoring was performed, according to the method described by Okazaki et al., 2001 [29], to evaluate the pulmonary inflammation and fibrosis in which: 0 , normal lung tissue; 1 , pulmonary inflammation and fibrosis affecting $<25 \%$ of the lung; 2 , pulmonary lesions affecting $25-50 \%$ of the 
lung; and 3, lesions affecting $>50 \%$ of the lung. The mean of the lesion scores was estimated for five lung sections per mouse.

\subsubsection{Statistical Analysis}

Data for the in vivo experiment are presented as mean \pm S.E. Statistical significance of the data was analyzed using SPSS program (Statistical Package for Social Science) version 16. For comparison, One-Way analysis of variance (ANOVA) test and post-comparison was carried out with Duncan's Multiple Range Test for post hoc analysis. Statistical significance was acceptable to a level of $p \leq 0.05$.

\subsection{Molecular Modelling Study}

The X-ray crystal structure of human glucocorticoid receptor (PDB ID1M2Z; $2.5 \mathrm{~A}^{\circ}$ ) co-crystalized with its ligand, dexamethasone, was downloaded from protein data bank (www.pdb.org). The structure of the enzyme was established using the default protein preparation protocol of Accelry's discovery studio 2.5 (Accelrys ${ }^{\circledR}$, Inc., San Diego, CA, USA). Molecular modelling studies were done using Accelry's discovery studio 2.5 (Accelrys ${ }^{\circledR}$, Inc., San Diego, CA, USA) according to what was previously reported [30-32] and the binding free energies were calculated applying the following equation:

$$
\Delta \mathrm{G}_{\text {binding }}=\mathrm{E}_{\text {complex }}-\left(\mathrm{E}_{\mathrm{GR}}+\mathrm{E}_{\text {ligand }}\right)
$$
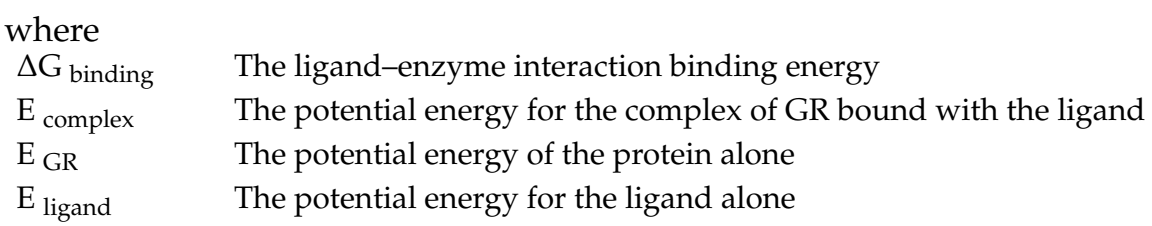

\section{Conclusions}

In conclusion, the investigations of the current study revealed that the essential oil of $P$. roxburghii bark could serve as a potent anti-inflammatory natural candidate as evidenced from the in vivo study. Molecular docking of the major oil components on human glucocorticoid receptors showed affinity to the binding site as compared to the dexamethasone, the highly potent anti-inflammatory agent. This further consolidates its ethnomedicinal value as an anti-inflammatory agent. Its probable mode of action could be partly interpreted by virtue of its agonistic effect on the glucocorticoid receptor and hence could be used as a promising natural anti-inflammatory candidate. Nevertheless, these findings should be supported by further in vitro, in vivo, and finally clinical trials to confirm the claimed activity.

Supplementary Materials: Supplementary materials are available online.

Acknowledgments: The authors would like to thank Azza Hassan; associate professor of Pathology, Faculty of Veterinary Medicine, Cairo University, Giza, Egypt for her help in histopathological examination and lesion score evaluation.

Author Contributions: R.M.L., F.S.Y. and M.L.A. participated in the isolation of essential oil, interpretation of the GC chromatogram, in vitro anti-inflammatory assessment and in carrying out the docking part, then writing the manuscript. M.M.A. D. performed the in vivo experiment, analyzed the data and wrote the in vivo part in the manuscript. S.A.R. supervised in vitro anti-inflammatory assessment and revised the whole manuscript.

Conflicts of Interest: The authors declare no conflict of interest.

\section{References}

1. Oyedapo, O.; Adewunmi, C.; Iwalewa, E.; Makanju, V. Analgesic, antioxidant and anti-inflammatory related activities of $2^{1}$-hydroxy-2,4 $4^{1}$-dimethoxychalcone and 4-hydroxychalcone in Mice. J. Biol. Sci. 2008, 8, 131-136.

2. Stankov, S.V. Definition of inflammation, causes of inflammation and possible anti-inflammatory strategies. Open Inflamm. J. 2012, 5, 1-9. [CrossRef] 
3. El-Readi, M.Z.; Eid, H.H.; Ashour, M.L.; Eid, S.Y.; Labib, R.M.; Sporer, F.; Wink, M. Variations of the chemical composition and bioactivity of essential oils from leaves and stems of Liquidambar styraciflua (Altingiaceae). J. Pharm. Pharmacol. 2013, 65, 1653-1663. [CrossRef] [PubMed]

4. Tapiero, H.; Ba, G.N.; Couvreur, P.; Tew, K. Polyunsaturated fatty acids (PUFA) and eicosanoids in human health and pathologies. Biomed. Pharmacother. 2002, 56, 215-222. [CrossRef]

5. Kaushik, D.; Kumar, A.; Kaushik, P.; Rana, A. Analgesic and anti-inflammatory activity of Pinus roxburghii Sarg. Adv. Pharmacol. Sci. 2012, 2012, 245431. [CrossRef] [PubMed]

6. Kaushik, P.; Kaushik, D.; Khokra, S.L. Ethnobotany and phytopharmacology of Pinus roxburghii Sarg: A plant review. J. Integr. Med. 2013, 11, 371-376. [CrossRef] [PubMed]

7. Rashid, S.; Ahmad, M.; Zafar, M.; Sultana, S.; Ayub, M.; Khan, M.; Yaseen, G. Ethnobotanical survey of medicinally important shrubs and trees of Himalayan region of Azad Jammu and Kashmir, Pakista. J. Ethnopharmacol. 2015, 166, 340-351. [CrossRef] [PubMed]

8. Khan, I.; Singh, V.; Chaudhary, A.K. Hepatoprotective activity of Pinus roxburghii Sarg. wood oil against carbon tetrachloride and ethanol induced hepatotoxicity. Bangladesh J. Pharmacol. 2012, 7, 94-99. [CrossRef]

9. Sharma, A.; Goyal, R.; Sharma, L. Potential biological efficacy of Pinus plant species against oxidative, inflammatory andmicrobial disorders. BMC Complement. Altern. Med. 2016, 16, 35. [CrossRef]

10. Shah, W.A.; Qadir, M.; Banday, J.A. GC-MS analysis, antibacterial, antioxidant and anticancer activity of essential oil of Pinus roxburghii from Kashmir, India. Int. J. Pharmacol. Res. 2014, 4, 61-64.

11. Gülçin, İ.; Büyükokuroğlu, M.E.; Oktay, M.; Küfrevioğlu, Ö.İ. Antioxidant and analgesic activities of turpentine of Pinus nigra Arn. subsp. pallsiana (Lamb.) Holmboe. J. Ethnopharmacol. 2003, 86, 51-58. [CrossRef]

12. Süntar, I.; Tumen, I.; Ustün, O.; Keleş, H.; Akkol, E.K. Appraisal on the wound healing and anti-inflammatory activities of the essential oils obtained from the cones and needles of Pinus species by in vivo and in vitro experimental models. J. Ethnopharmacol. 2012, 139, 533-540. [CrossRef] [PubMed]

13. Neves, J.M.; Matos, C.; Moutinho, C.; Queiroz, G.; Gomes, L.R. Ethnopharmacological notes about ancient uses of medicinal plants in Trás-os-Montes (northern of Portugal). J. Ethnopharmacol. 2009, 124, 270-283. [CrossRef] [PubMed]

14. Satyal, P.; Paudel, P.; Raut, J.; Deo, A.; Dosoky, N.S.; Setzer, W.N. Volatile constituents of Pinus roxburghii from Nepal. Pharmacogn. Res. 2013, 5, 43-48.

15. Anilkumar, K.M. Ethnomedicinal plants as anti-inflammatory and analgesic agents. In Ethnomedicine: A Source of Complementary Therapeutics; Chattopadhyay, D., Ed.; Research Signpost: Kerala, India, 2010.

16. Sehgal, N.; Smith, H.S.; Manchikanti, L. Peripherally acting opioids and clinical implications for pain control. Pain Physician 2011, 14, 249-258. [PubMed]

17. Cashman, J.N. The mechanisms of action of NSAIDs in analgesia. Drugs 1996, 52, 13-23. [CrossRef] [PubMed]

18. Pertwee, R.G. Pharmacology of cannabinoid CB1 and CB2 receptors. Pharmacol. Ther. 1997, 74, 129-180. [CrossRef]

19. Cutroneo, K.R.; Sterling, K.M. A molecular basis for bleomycin-induced pulmonary fibrosis. Chest J. 1986, 89, 121S-122S. [CrossRef]

20. Dik, W.; McAnulty, R.; Versnel, M.; Naber, B.; Zimmermann, L.; Laurent, G.; Mutsaers, S. Short course dexamethasone treatment following injury inhibits bleomycin induced fibrosis in rats. Thorax 2003, 58, 765-771. [CrossRef] [PubMed]

21. Rhen, T.; Cidlowski, J.A. Antiinflammatory action of glucocorticoids-New mechanisms for old drugs. N. Engl. J. Med. 2005, 353, 1711-1723. [CrossRef] [PubMed]

22. Adams, R.P. Identification of Essential oil Components by Gas Chromatography/Mass Spectrometry, 4th ed.; Allured Books: Carol Stream, IL, USA, 2009; p. 804.

23. Youssef, F.S.; Hamoud, R.; Ashour, M.L.; Singab, A.N.; Wink, M. Volatile oils from the aerial parts of Eremophila maculata and their antimicrobial activity. Chem. Biodivers. 2014, 11, 831-841. [CrossRef] [PubMed]

24. Howlett, A.; Barth, F.; Bonner, T.; Cabral, G.; Casellas, P.; Devane, W.; Felder, C.; Herkenham, M.; Mackie, K.; Martin, B. International Union of Pharmacology. XXVII. Classification of cannabinoid receptors. Pharmacol. Rev. 2002, 54, 161-202. [CrossRef] [PubMed]

25. Karimfar, M.H.; Rostami, S.; Haghani, K.; Bakhtiyari, S.; Noori-Zadeh, A. Melatonin alleviates bleomycin-induced pulmonary fibrosis in mice. J. Biol. Regul. Homeost. Agents 2015, 29, 327-334. [PubMed]

26. Nishikimi, M.; Appaji, N.; Yagi, K. The occurrence of superoxide anion in the reaction of reduced phenazine methosulfate and molecular oxygen. Biochem. Biophys. Res. Commun. 1972, 46, 849-854. [CrossRef] 
27. Aebi, H. Catalase in vitro. Methods Enzymol. 1984, 105, 121-126. [PubMed]

28. Mihara, M.; Uchiyama, M. Determination of malonaldehyde precursor in tissues by thiobarbituric acid test. Anal. Biochem. 1978, 86, 271-278. [PubMed]

29. Okazaki, T.; Nakao, A.; Nakano, H.; Takahashi, F.; Takahashi, K.; Shimozato, O.; Takeda, K.; Yagita, H.; Okumura, K. Impairment of bleomycin-induced lung fibrosis in CD28-deficient mice. J. Immunol. 2001, 167, 1977-1981. [CrossRef] [PubMed]

30. Youssef, F.S.; Ashour, M.L.; Ebada, S.S.; Sobeh, M.; El-Beshbishy, H.A.; Singab, A.N.; Wink, M. Antihyperglycaemic activity of the methanol extract from leaves of Eremophila maculata (Scrophulariaceae) in streptozotocin-induced diabetic rats. J. Pharm. Pharmacol. 2017, 69, 733-742. [CrossRef] [PubMed]

31. Ashour, M.L.; Youssef, F.S.; Gad, H.A.; Wink, M. Inhibition of cytochrome P450 (CYP3A4) activity by extracts from 57 plants used in traditional chinese medicine (TCM). Pharmacogn. Mag. 2017, 13, 300-308. [PubMed]

32. Youssef, F.; Ashour, M.; Sobeh, M.; El-Beshbishy, H.; Singab, A.N.; Wink, M. Eremophila maculata-Isolation of a rare naturally-occurring lignan glycoside and the hepatoprotective activity of the leaf extract. Phytomedicine 2016, 23, 1484-1493.

Sample Availability: Samples of the essential oil of Pinus roxburghii are available from the authors. 